\title{
Effect of Socio-Demographic Factors on Zinc Status of Infants and Preschool Children in East Gojjam, Amhara Region of Ethiopia
}

\author{
Adamu Belay $^{1}$, Grace Marquis ${ }^{2}$ and Gulelat Desse ${ }^{3}$ \\ 1. Food Science and Nutrition Research, Ethiopian Public Health Institute, Addis Ababa, Ethiopia \\ 2. School of Dietetics and Human Nutrition, McGill University, Montreal, Canada \\ 3. Department of Food Science and Technology, Botswana College of Agriculture, Gaborone, Botswana
}

\begin{abstract}
Zinc deficiency is a public health concern and is the most prevalent micronutrient deficiencies in developing countries. The main objective of this study was to assess the prevalence and risk factors of zinc deficiency among infants and preschool children. Based on a community, the cross-sectional study was conducted in East Gojjam between October 2011 and April 2012. Two hundred and forty infants and preschool children were randomly selected in the study. Data on potential determinants of zinc deficiency were collected using a structured questionnaire. Serum zinc concentration was measured using atomic absorption spectrometer. Statistical analysis was done using ANOVA, independent sample student's $t$-test and linear regression model. The mean serum zinc concentration of infants and preschool children was $62.98( \pm 13.03) \mu \mathrm{g} / \mathrm{dL}$ in $95 \%$ confidence interval (CI) between 61.32 and 64.63 (i.e., $95 \%$ CI: $61.32,64.63$ ). About $57.1 \%$ of the subjects were zinc deficient. The main determinants of low serum zinc status of infants and preschool children were age and number of family members living on the same land. Zinc status of older children was $3.67 \mu \mathrm{g} / \mathrm{dL}(95 \% \mathrm{CI}:-5.58,-1.77)$ lower than children who were aged 6-10 months. Serum zinc status of infants and preschool children is decreased by $0.83 \mu \mathrm{g} / \mathrm{dL}(95 \% \mathrm{CI}:-1.36,-0.30)$ with each additional family member. Food insecurity, dietary diversity, sex, child health, anthropometric indices, maternal education and wealth index were not associated with serum zinc status. Zinc deficiency among infants and preschool children is highly prevalent. Such potential deficiencies require urgent attention, including complementary food preparation education, traditional phytate reduction method and family planning implementation recommended in the study area.
\end{abstract}

Key words: Serum zinc concentration, zinc deficiency, infant and preschool children.

\section{Introduction}

Zinc is vital micronutrient, which is essential for normal immune function and physical growth. Micronutrient deficiency, such as zinc, is important nutritional problems, is widespread in many developing countries, including Ethiopia, and remains as major problems among preschool children [1].

The importance of zinc is reflected by the numerous functions and activities, over which it exerts a regulatory role. Zinc is also needed for nucleic acid metabolism, protein synthesis, cellular differentiation

Corresponding author: Adamu Belay, M.Sc., research fields: food science and nutrition. E-mail: adamu_bel2000 (a)yahoo.com. and replication, as well as glucose metabolism and insulin secretion, since zinc is required for the structure and activity of more than 200 enzymes [2].

Lack of zinc in infants and preschool children is the leading cause of diseases, like diarrhea and pneumonia which can lead to high mortality rate according to International Zinc Nutrition Consultative Group (IZiNCG) and the World Health Organization (WHO) report in 2002. Zinc deficiency affects one-third of the world's population with estimations ranging from $4 \%$ to $73 \%$ across sub-regions in Sub-Saharan Africa, and about $1.4 \%$ of deaths were attributed to zinc deficiency in the world [3]. This situation is responsible for $4 \%$ of deaths and morbidity among 
infants and preschool children [4]. Also zinc deficiency is responsible for $16 \%$ of infections of lower respiratory tract, $18 \%$ of malaria and $10 \%$ of diarrhea diseases [5]. In Ethiopia, zinc deficiency has been estimated only by indirect methods, like stunting prevalence and the national food balance sheet data [5]. The etiology of zinc deficiency in a community is due to inadequate intake of zinc in food, infectious disease and genetic factors. Many factors seriously affect child growth and nutritional status, especially in developing countries, such as family size, educational status, parent's job and parent's socio-economic status, knowledge about proper nutrition, prenatal care, mother's age, mother's weight and newborn's sex [6].

Food consumption pattern in most of the rural area in Ethiopia is cereals, plant-based products and animal products. Animal products are the best sources of zinc, but they are not affordable for many rural communities, because economic status in rural area is low and thus only $5 \%$ of children consumed meat, fish or poultry and $8 \%$ consumed eggs during 2011 Ethiopian demographic and health survey. The consumption of iron-rich foods is more common in urban areas (22\%) than in rural areas (12\%) [7]. The extent of zinc deficiency among infants and preschool children remains unknown in many parts of the country. Therefore, the aim of this study was to determine the prevalence and risk factors of zinc deficiency among infants and preschool children in East Gojjam, Amhara region of Ethiopia.

\section{Methods}

This cross-sectional study was carried out between October 2011 and April 2012 as part of a baseline study about the effect of iodized salt on child cognitive development. The data collection took place in 12 districts (woredas) in East Gojjam zone, which is one of 11 administrative zones of Amhara region and is located at $150 \mathrm{~km}$ North-West of Addis Ababa, Ethiopia. One village (kebele) in each woreda was randomly selected. According to the 2007 Ethiopian census, this zone has a total population of $2,153,937$; only a small fraction (9.92\%) is urban, with an area of $14,000 \mathrm{~km}^{2}$; the zone has a population density of 153.80 people $/ \mathrm{km}^{2}$. The dominant crops in this zone include sorghum, teff, maize and haricot beans, which are grown for both consumption and commercial values.

\subsection{Sample Size}

Sample size adequate for estimating the prevalence of zinc deficiency was computed using single proportion sample size calculation formula with the inputs of $95 \%$ confidence level, $10 \%$ of margin of error and expected prevalence of zinc deficiency of $50 \%$; 96 children per age group were expected to fulfill a total sample size of 288 children.

\subsection{Sampling Technique}

To determine the prevalence of zinc status, 240 mothers and their children under 60 months of age from 13 woredas in East Gojjam were randomly selected; from each woreda, one rural kebele was selected randomly. From all selected kebeles of East Gojjam, 90 children from 6-10 months, 70 children from 18-22 months and 80 children from 54-60 months were recruited to help government-paid health extension workers and the census team. These children are respectively selected from 6-10, 18-22 and 54-60 months children who have relatively similar psychology development level. In the baseline study, the census team listed all children from each age group in each sub-kebele by visiting house-to-house in collaboration with health extension workers and voluntary health workers. Simple random selection of eligible subjects from the listed households in each kebele was done.

\subsection{Data Collection Method}

Mothers were interviewed concerning the family's socio-economic and demographic information, child's health, food diversity and food security to assess the potential determinants of zinc deficiency. The food 
diversity questionnaire was administrated to mothers and evaluated by using household dietary diversity score (HDDS) [8]. The food insecurity questionnaire was adopted from food and nutrition technical assistance (FANTA) and evaluated by using household food insecurity access scale (HFIAS) on the bases of the average mean of nine indicators of the food security questionnaires [9]. The length of infants and young children aged 6-22 months was measured in a recumbent position and the height of children aged 24 months and older was measured in a standing-up position to the nearest $0.1 \mathrm{~cm}$ according to standard procedures [10]. Body weight of children was recorded to the nearest $0.1 \mathrm{~kg}$ by using Tanita scale.

\subsection{Blood Sample Collection, Serum Extraction and Zinc Level Determination}

$5 \mathrm{~mL}$ of venous blood was drawn using stainless steel butterfly needle, and was collected into trace element-free evacuated blood collection tubes (Vacutainers, $6 \mathrm{~mL}$ and royal blue top) without anticoagulant for processing serum. Blood samples were placed in ice box, allowed to clot for $30 \mathrm{~min}$ and consecutively centrifuged at 3,000 rpm for $10 \mathrm{~min}$. Serum was extracted and transferred to vials. Sera were stored at $-80{ }^{\circ} \mathrm{C}$ until serum zinc analysis is conducted. Serum zinc was determined at Food, Medicine and Health Care Administration and Control Authority (FMHACA) laboratory by using Shimadzu Flame Atomic Absorption Spectroscopy (AA 6800 model, Japan) with an air-acetylene flame at a wavelength of $213.9 \mathrm{~nm}$ and a slit width of $0.7 \mathrm{~nm}$. $200 \mu \mathrm{L}$ of serum sample were added into a trace metal free plastic test tube and diluted by addition of $6 \%$ butanol in 1:5 ratios. Calibration curve of the Atomic Absorption Spectrophotometer (AAS, Shimadzu) was carried out using series of standards of zinc $(0,0.1$, $0.2,0.3$ and $0.4 \mathrm{ppm}$ ) by dilution from stock of 1,000 ppm AAS zinc standards. Each series of standards were diluted with $5 \%$ glycerol to make the same viscosity of the serum samples. Internal quality control was done according to IZiNCG 2004 recommendation. Zinc deficiency was defined as a serum zinc level of less than $65 \mu \mathrm{g} / \mathrm{dL}$ [11].

\subsection{Data Analysis}

Anthropometric indices were calculated using Emergency Nutrition Assessment SMART 2011 software. The indices are expressed as standard deviation units from the median values of the WHO (2006) standard reference data of US children. The wealth index was calculated based on the ownership of selected household assets, size of agricultural land and quantity of livestock. Wealth index quintiles (poorest, poorer, middle, richer and richest) were computed using principal component analysis (PCA).

The statistical analysis was carried out using SPSS 16 for windows. Descriptive analysis was done by using mean, frequency and percentage. Independent sample student's $t$-test and one way analysis of variance (ANOVA) with Post-Hoc Tukey tests were performed to test the existence of significant association between zinc concentration and independent variables. Linear regression analysis was applied to control confounders.

\subsection{Ethical Considerations}

The study proposal of the main project was presented on the scientific forum of the Ethiopian Health and Nutrition Research Institute (EHNRI) and approved at Ethical Clearance Committee and McGill University (Canada) Ethical Review Board. The study was also explained to officials of the Zonal Administration, Zonal Health Department of East Gojjam and administrative officials of all woredas. Data collectors read the consent form that clarifies the purpose of the study, study confidentiality and the voluntary participation right of mothers; besides, all willing participator should put their signature on the consent form. 


\section{Results}

\subsection{Background Information about Study Subjects}

A total of 240 children aged 6-60 months were enrolled from 13 woredas of East Gojjam and all infants and preschool children were included in serum analysis. The response rate was $83.3 \%$. In this study, all the study areas were rural. The mean child age of the participants was $28.17( \pm 21.57)$ months.

In all studied children, 105 (43.8\%) were female and $135(56.2 \%)$ were male. Infants and preschool children enrolled in the study were categorized into three age groups (group 1: 6-10 months (37.50\% of the total), group 2: $18-22$ months $(29.20 \%$ of the total) and group 3: 54-60 months (33.30\% of the total)). In the total number of mothers of the selected child, 213 $(89.10 \%)$ were illiterate, $26(10.10 \%)$ were literate and all household heads were farmers. In the study area, the Amharic language, Amhara ethnicity and Orthodox religion followers predominated. Household family members who live on the same land were classified into three groups (small: up to five members, medium: 6-10 members and large: 11 or more), and they held $44.20 \%, 48.70 \%$ and $7.10 \%$, respectively. The average number of household members living on the same land was $6.37( \pm 2.99)$ persons. The wealth index of the participants was classified based on the ownership of selected household assets, size of agricultural land, quantity of livestock and materials used for housing construction by PCA method. Statistical figure of socio-demographic and housing characteristics assumed to be associated with zinc status of children is displayed in Table 1.

\subsection{Prevalence of Zinc Deficiency}

The mean serum zinc concentration of infants and preschool children was $62.98( \pm 13.01) \mu \mathrm{g} / \mathrm{dL}(95 \%$ CI: 61.32, 64.63) (Fig. 1). The value ranged from $28.05 \mu \mathrm{g} / \mathrm{dL}$ to $108.57 \mu \mathrm{g} / \mathrm{dL}$. Serum zinc level for 6-10, 18-22 and 54-60 months age group were 67.08 $( \pm 13.21), 61.41( \pm 10.71)$ and $59.74( \pm 13.62) \mu \mathrm{g} / \mathrm{dL}$, respectively. The zinc status across age groups were statistically significant $(F=7.875, P=0.000)$. Serum zinc level of the 6-10 months age group was significantly different from $18-22$ months $(P=0.015)$ and 54-60 months age groups $(P=0.001)$. But the mean zinc status between 18-22 months and 54-60

Table 1 Socio-demographic characteristic of the study subjects in East Gojjam, Ethiopia, April 2012.

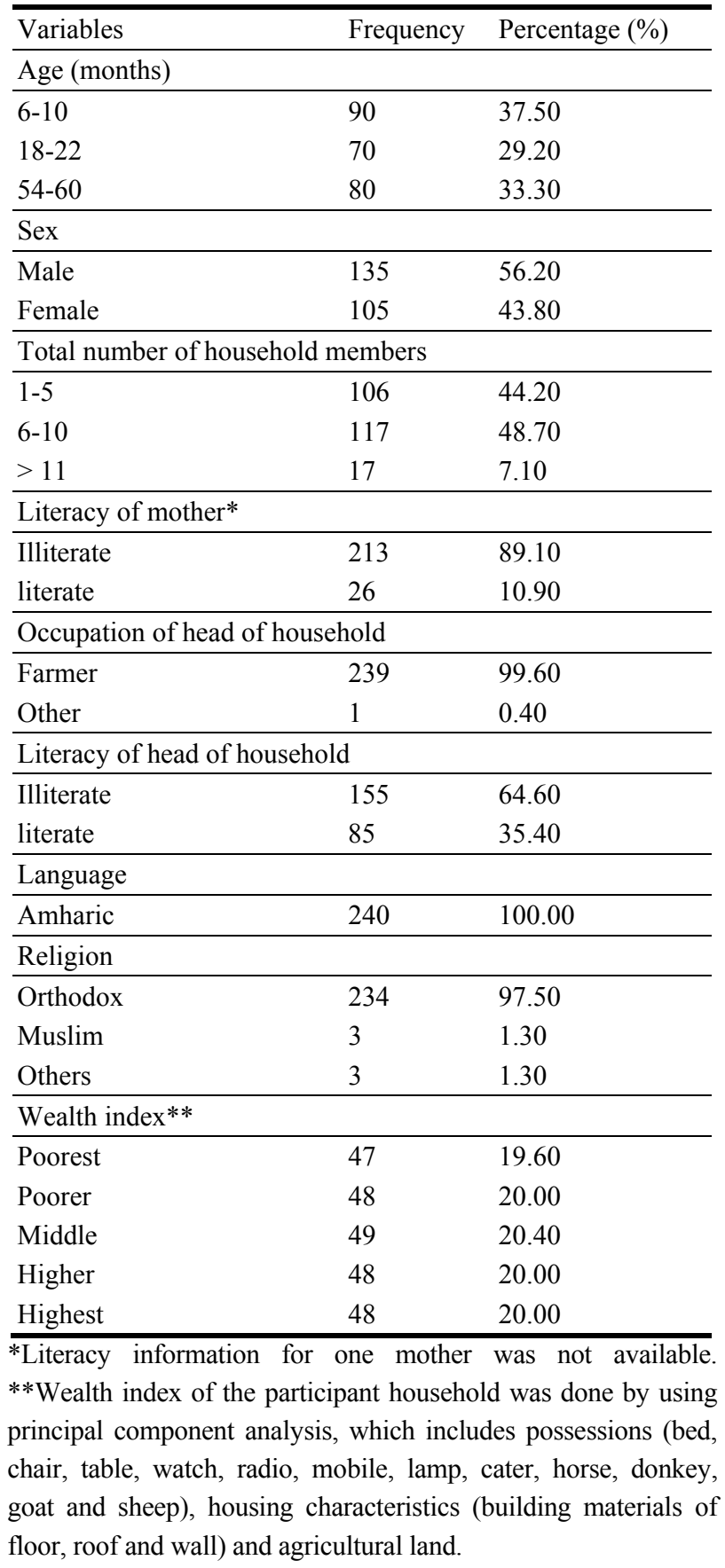




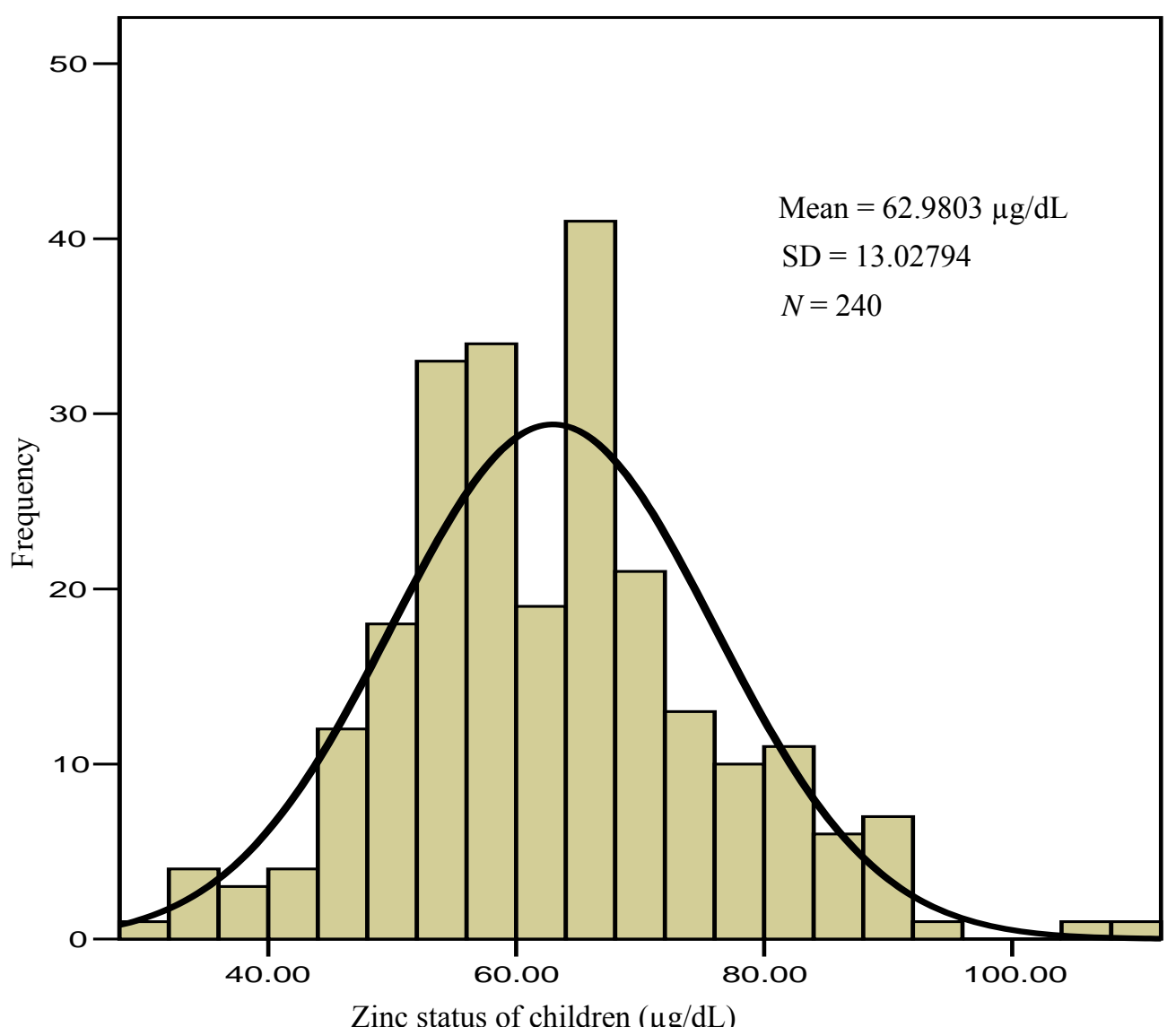

Fig. 1 Distribution curve of zinc status $(\mu \mathrm{g} / \mathrm{dL})$ of infant and preschool children aged 6-60 months in East Gojjam.

months age groups were not significantly different $(P$ $=0.702)($ Table 2$)$.

Among the study population, $57.10 \%$ of infants and preschool children were zinc deficient. The prevalence of zinc deficiency of infants and preschool children for 6-10, 18-22 and 54-60 months age groups were $44.4 \%, 61.4 \%$ and $67.5 \%$, respectively.

\subsection{Socio-Demographic Factors and Zinc Deficiency}

Infants and preschool children's age was negatively associated with zinc status. This means that as the age group increased, the mean serum zinc decreased. The mean serum zinc levels for age 6-10, 18-22 and 54-60 months were $67.08( \pm 13.20), 61.41( \pm 10.71)$ and $59.74( \pm 13.62) \mu \mathrm{g} / \mathrm{dL}$, respectively. Zinc status among age groups were statistically significant $(F=$ $7.875, P=0.000$ ). The mean serum zinc level for males and female were $62.60( \pm 12.31) \mu \mathrm{g} / \mathrm{dL}$ and
$63.47( \pm 13.92) \mu \mathrm{g} / \mathrm{dL}$, respectively. Sex and mean serum zinc status were not significantly associated $(t=$ $0.611, P=0.611)$. The mean serum zinc level for illiterates and literate mothers' children were $62.81( \pm$ $13.51) \mu \mathrm{g} / \mathrm{dL}$ and $64.66( \pm 8.72) \mu \mathrm{g} / \mathrm{dL}$, respectively, and did not differ significantly $(t=0.495, P=0.495)$.

The total number of family members, who live together on the same land, were divided into three groups (small: up to five members, medium: 6-10 members and large: 11 or more) to investigate the effect of family size on the serum zinc level of children. There was a significant difference between the total numbers of people living in the same house and serum zinc level $(F=3.501, P=0.032)$. The mean serum zinc level of the selected child, who had 1-5, 6-10 and $>11$ household members, were $64.44( \pm$ $11.91), 62.73( \pm 13.72)$ and $55.59( \pm 13.13) \mu \mathrm{g} / \mathrm{dL}$, respectively. Mean serum zinc level of infants and 
children live in a household with 1-5 members was different from children who live in a household with more than 11 family members $(P=0.025)$.

Data was categorized into five wealth status levels by using principal component analysis. Serum zinc concentration of children, who belong to wealth index of poorest, poorer, middle, higher and highest, had serum zinc concentration of $61.74( \pm 13.91), 60.64( \pm$ 12.32), 64.99 ( \pm 14.40$), 64.79( \pm 13.01)$ and $62.64( \pm$ 11.32) $\mu \mathrm{g} / \mathrm{dL}$, respectively; the groups did not differ significantly $(F=0.395, P=0.395)$ (Table 2).

The level of household food insecurity was assessed using HFIAS. The scale appraises the occurrence of nine food insecurity related events in the household in the preceding four weeks of the survey. Each event that took place resulted in a score (one or zero). Mean serum zinc status of children who lived in food secure households and children who lived in food insecure were $64.06( \pm 13.26) \mu \mathrm{g} / \mathrm{dL}$ and $61.89( \pm 12.79)$ $\mu \mathrm{g} / \mathrm{dL}$, respectively; the difference was not statistically significant $(t=1.412, P=0.199)$ (Table 2$)$.

\subsection{Zinc Deficiency and Anthropometric Indices}

The analysis of children's nutritional status, based on the standard deviation units from the median value for the three anthropometric indices (height-for-age,

Table 2 Socio-Demographic factors and zinc status of aged 6-60 months children in East Gojjam Ethiopia, April 2012.

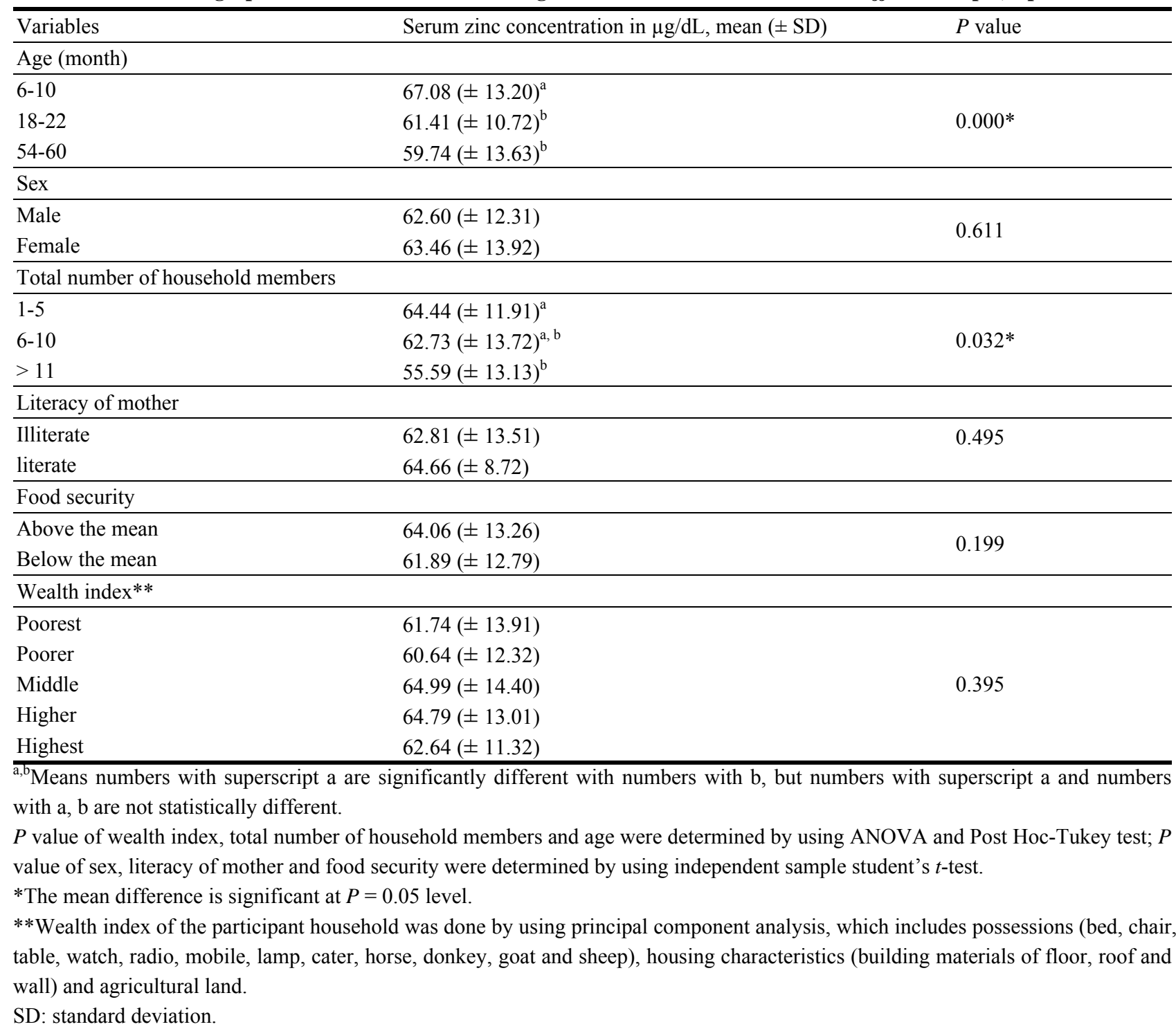


weight-for-age and weight-for-height), revealed that 43.30\% (95\% CI: 37.10, 49.60), 19.70\% (95\% CI: $15.20,25.30)$ and $5.90 \%(95 \%$ CI: $3.60,9.70)$ of the total 240 children included in the survey were found to be stunted, underweight and wasted, respectively.

Males had a higher prevalence of stunting than females $(56.3 \%$ vs. $43.8 \%, P=0.019)$. Among the three age groups, 6-10 months age group (31.11\%) had the lowest prevalence in stunting relative to $18-22$ months $(61.76 \%)$ and 54-60 months (41.25\%) age groups $(P=0.000)$. The mean height-for-age $\mathrm{Z}$-score (HAZ) of infants and preschool children who aged 6-10, 18-22 and 54-56 months were -1.32 ( \pm 1.17$)$, $-2.19( \pm 1.06)$ and $-1.84( \pm 1.11)$, respectively $(F=$ $9.356, P=0.000)$. The mean serum zinc concentration of those who were stunted was $63.66( \pm 13.21) \mu \mathrm{g} / \mathrm{dL}$, while the mean serum zinc concentration of non-stunted subjects was $62.58( \pm 12.90) \mu \mathrm{g} / \mathrm{dL}$. The mean concentration of zinc between the two groups were not significant $(P=0.527)$. Also, there were no statistical difference in mean serum zinc status of infants and preschool children who were under weight $(P=0.869)$ and thin $(P=0.686)$ (Table 3$)$.

\subsection{Zinc Deficiency and Child Health}

We observed that $14.6 \%(35 / 239)$ of the children presented episodes of fever and $19.3 \%$ (46/239) of the children presented episodes of diarrhea during the 14 days preceding the enrollment day of interview and blood collection in the study. The mean zinc serum levels level of children with episodes of fever and children with no such episode were $62.62( \pm 14.31)$ $\mu \mathrm{g} / \mathrm{dL}$ and $63.11( \pm 12.80) \mu \mathrm{g} / \mathrm{dL}$, respectively; the mean serum zinc level difference between the groups was not statistically significant $(t=0.200, P=0.842$ ). The mean serum zinc of children who were presented episodes of diarrhea and children with no such episode were $63.83( \pm 12.51) \mu \mathrm{g} / \mathrm{dL}$ and $62.84( \pm 13.21) \mu \mathrm{g} / \mathrm{dL}$, respectively; mean serum zinc of the two groups were not statistically significant $(t=-0.478, P=0.644)$ (Table 4).

\subsection{Zinc Deficiency and Food Diversity}

In this study, most of the participants consumed grains (teff, sorghum, millet, maize, barley and rice) and legume (mostly beans), few participants $(n=4)$ consumed lentil products among six food categories within $24 \mathrm{~h}$. There was a minimum consumption of vegetables, very few children consumed meat products, and only $17.5 \%$ of children had milk. Among the study subjects, only 2.5\% (6/240) of children consumed meat and egg products (Table 5).

As shown in Table 5, statistical significances found in mean serum zinc concentration values between infants and preschool children who ate cereal group $(t$ $=2.602, P=0.010)$ and legume products $(t=2.230, P$ $=0.027)$. But there was no statistical difference in mean serum zinc status of infants and preschool children who

Table 3 Anthropometric indices and zinc status of children aged 6-60 months in East Gojjam Ethiopia, April, 2012.

\begin{tabular}{|c|c|c|c|c|c|c|}
\hline \multirow{2}{*}{ Anthropometric indices } & \multicolumn{2}{|c|}{ Frequency of sex } & \multirow{2}{*}{$\begin{array}{l}\text { Total frequency } \\
(238)\end{array}$} & \multirow{2}{*}{$\begin{array}{c}\text { Percentage } \\
(\%)\end{array}$} & \multirow{2}{*}{$\begin{array}{l}\text { Serum zinc concentration in } \\
\mu \mathrm{g} / \mathrm{dL} \text {, mean }( \pm \mathrm{SD})\end{array}$} & \multirow{2}{*}{$P$ value } \\
\hline & Male & Female & & & & \\
\hline \multicolumn{7}{|l|}{ Height-for-age } \\
\hline$<-2$ Z-score & 67 & 36 & 103 & 43.3 & $63.66( \pm 13.21)$ & \multirow{2}{*}{0.527} \\
\hline$>-2$ Z-score & 67 & 68 & 135 & 56.7 & $62.58( \pm 12.90)$ & \\
\hline \multicolumn{7}{|l|}{ Weight-for-age } \\
\hline$<-2$ Z-score & 32 & 15 & 47 & 19.7 & $62.94( \pm 12.89)$ & \multirow{2}{*}{0.869} \\
\hline$>-2$ Z-score & 102 & 89 & 191 & 80.3 & $63.53( \pm 15.60)$ & \\
\hline \multicolumn{7}{|l|}{ Weight-for-height } \\
\hline$<-2$ Z-score & 10 & 4 & 14 & 5.9 & $62.88( \pm 13.11)$ & \multirow{2}{*}{0.686} \\
\hline$>-2$ Z-score & 124 & 100 & 224 & 94.1 & $63.74( \pm 12.89)$ & \\
\hline
\end{tabular}

$P$ value was determined by using independent sample student's $t$-test; $Z$-score is a statistical measure that reflects the relative deviance form the median value/standard ( $<-2 \mathrm{Z}$-score indicates the child is stunted; $>-2 \mathrm{Z}$-score indicates the child is not-stunted). 
Effect of Socio-Demographic Factors on Zinc Status of Infants and Preschool Children in East Gojjam, Amhara Region of Ethiopia

Table 4 Child health and zinc status of the study subjects in East Gojjam Ethiopia, April, 2012.

\begin{tabular}{llll}
\hline Variable & Frequency $(239)$ & Serum zinc concentration in $\mu \mathrm{g} / \mathrm{dL}$, mean $( \pm \mathrm{SD})$ & $P$ value \\
\hline Fever & & & \\
\hline No & 204 & $63.11( \pm 12.80)$ & 0.842 \\
Yes & 35 & $62.62( \pm 14.31)$ & \\
\hline Diarrhea & & & 0.644 \\
\hline No & 193 & $62.84( \pm 13.21)$ & \\
Yes & 46 & $63.83( \pm 12.51)$ & \\
\hline
\end{tabular}

$P$ value was determined by using independent sample student's $t$-test; SD: standard deviation.

Table 5 Dietary diversity and zinc status of children aged 6-60 months in East Gojjam Ethiopia, April 2012.

\begin{tabular}{|c|c|c|c|}
\hline Variable & Frequency (240) & Serum zinc concentration in $\mu \mathrm{g} / \mathrm{dL}$, mean $( \pm \mathrm{SD})$ & $P$ value \\
\hline \multicolumn{4}{|c|}{ Grains and tubers } \\
\hline No & 36 & $68.12( \pm 11.33)$ & \multirow{2}{*}{$0.01 *$} \\
\hline Yes & 204 & $62.07( \pm 13.12)$ & \\
\hline \multicolumn{4}{|c|}{ Legumes and nuts } \\
\hline No & 75 & $65.74( \pm 12.91)$ & \multirow{2}{*}{$0.027 *$} \\
\hline Yes & 165 & $61.73( \pm 12.92)$ & \\
\hline \multicolumn{4}{|c|}{ Milk and milk products } \\
\hline No & 198 & $62.81( \pm 13.01)$ & \multirow{2}{*}{0.670} \\
\hline Yes & 42 & $63.76( \pm 13.31)$ & \\
\hline \multicolumn{4}{|l|}{ Meat } \\
\hline No & 234 & $63.11( \pm 12.02)$ & \multirow{2}{*}{0.338} \\
\hline Yes & 6 & $57.94( \pm 14.41)$ & \\
\hline \multicolumn{4}{|l|}{ Eggs } \\
\hline No & 234 & $63.01( \pm 13.02)$ & \multirow{2}{*}{0.399} \\
\hline Yes & 6 & $58.54( \pm 7.52)$ & \\
\hline \multicolumn{4}{|c|}{ Vitamin A rich food } \\
\hline No & 220 & $63.15( \pm 13.01)$ & \multirow{2}{*}{0.493} \\
\hline Yes & 20 & $61.06( \pm 13.32)$ & \\
\hline
\end{tabular}

$P$ value was determined by using independent sample student's $t$-test. ${ }^{*}$ Means the mean difference is significant at $P=0.05$.

Grain and tuber: teff, sorghum, wheat, millet, maize, barely, rice and cassava; legumes and nut: bean, chick pea, lentil and nut; milk and milk product: milk; meat: beef, lamb, goat and fish; vitamin A rich food: papaya, peaches, tringo, mango, tomato, sweet potatoes and leaf vegetables.

ate milk and milk products $(t=-0.427, P=0.670)$, meat $(t=0.959, P=0.338)$, egg $(t=0.844, P=0.399)$ and vitamin A rich foods groups $(t=0.687, P=0.493)$ in comparison with their counterpart (Table 5).

As shown in Fig. 2, children above the subjects who consumed exclusive breast feeding had a better zinc status than the children who consumed group 1 and 2 $(P=0.020)$. There was no different zinc status between infants and preschool children who were breastfed and children who ate one, three, four and five food categories.

The linear regression model analysis was used to control the confounder in distal and proximate factors. In the distal factor model, the number of family members who live on the same land was the main determinant factor in zinc status of infants and preschool children. This factor was significant in both unadjusted $(P=0.006)$ and adjusted linear regression analysis $(P=0.006)$ (Table 6$)$, but maternal education, food security and economic status were not significant contributors on zinc status of infant and preschool children in both unadjusted and adjusted linear regression analysis (Table 6).

In proximate factor model, dietary diversity was 


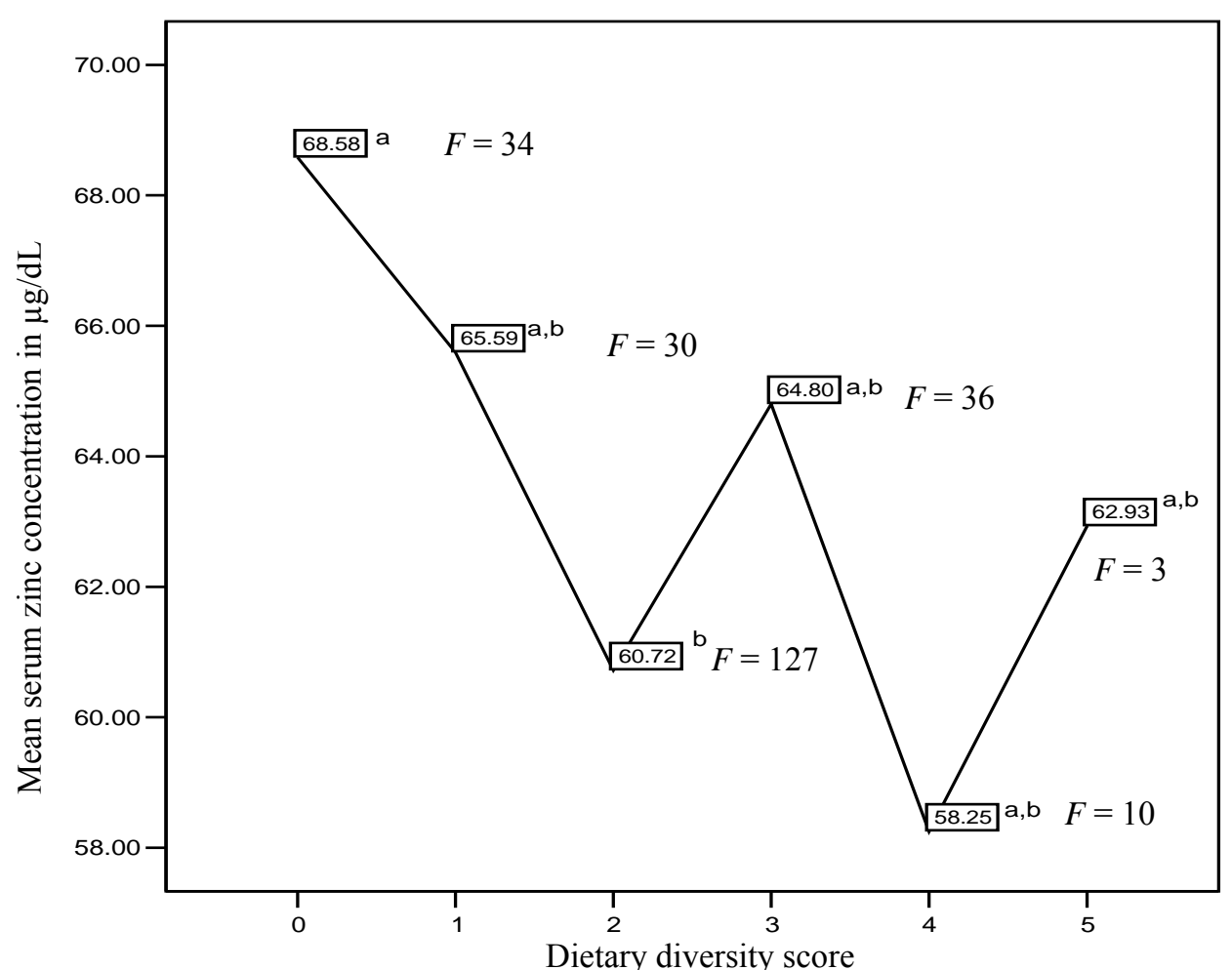

Fig. 2 Dietary diversity score and zinc status of aged 6-60 months children in East Gojjam Ethiopia, April, 2012.

Dietary diversity score: the categories were determined by first asking if the mothers had fed their children a particular type of food (30 different types) in the previous $24 \mathrm{~h}$, and then a score was calculated to determine how many different types of food groups were consumed by children.

${ }^{a, b}$ Means numbers with superscript a are significantly different with numbers with $b$, but numbers with superscript a and numbers with $\mathrm{a}, \mathrm{b}$ are not statistically different.

$0=$ exclusive breastfeeding; $F$ : the frequency of infants and preschool children who ate group $0,1,2,3,4$ and 5 foods were 34,30 , $127,36,10$ and 3 , respectively.

significant before adjustment, but there was no association after adjustment. Age was the main factor which influenced zinc status of infant and preschool children. Association with age was significant in both unadjusted and adjusted linear regression analysis. But, sex, height-for-age, fever and diarrhea were not significantly associated with zinc status of children.

As shown in Table 7, age and total number of household living on the family land shows significances with children serum zinc status $(P<0.05)$; but in the final model, dietary diversity shows statistical significance without strong association with serum zinc status of infants and preschool children $(P=0.104)$.

\section{Discussion}

Among the participants, $57.1 \%$ of the children were zinc deficient. Many subjects in all age groups had zinc levels below the cutoff point used to define zinc deficiency. The reason might be that consumption of animal sources is mostly limited to occasional public holidays, which indicated minimal intake in most of the rural areas of Ethiopia. Thus, one can expect a high prevalence of zinc deficiency in Ethiopia [12]. Moreover, many studies conducted in developing countries showed that the prevalence of zinc deficiency was higher in rural area than in urban area [13-16].

There is a lack of agreement on the normal variation in plasma zinc values according to age. Wouwe and Waser [17] found no age-dependent variation in total serum zinc among healthy Dutch infants and children. Likewise, Karr et al. [18] estimated 
Table 6 Linear regression model analysis of distal or proximal model of children aged 6-60 months in East Gojjam, April 2012.

\begin{tabular}{lllllllll}
\hline \multirow{2}{*}{ Model } & Independent variables & \multicolumn{9}{c}{ Unadjusted } & \multicolumn{5}{c}{ Adjusted } \\
& & $\begin{array}{l}\text { Unstandardized } \\
\text { coefficient }\end{array}$ & $t$ & $P$ & $\begin{array}{l}\text { Unstandardized } \\
\text { coefficient }\end{array}$ & $t$ & $P$ & Adjusted $R$ \\
square
\end{tabular}

Literacy of mother: education status of mother was categorized into two: $1=$ illiterate or $2=$ literate.

Number of family: total number of household members living on family land.

Food security: the level of household food insecurity was assessed using HFIAS and categorized into two groups: $1=$ above and $2=$ below the mean of nine point.

Wealth index: wealth index of the participant household was done by using principal component analysis, which includes possessions (bed, chair, table, watch, radio, mobile, lamp, cater, horse, donkey, goat and sheep), housing characteristics (building materials of floor, roof and wall) and agricultural land.

Age categorized: infants and preschool children were categorized into three age groups: $1=6-10$ months, $2=18-22$ months and $3=$ 54-60 months.

Sex: categorized into male and female, $1=$ male, $2=$ female.

Diarrhea: yes or no category $(0=$ no, $1=$ yes $)$, the children presented episodes of diarrhea during the 14 days preceding enrollment of the day of interview.

Fever: yes or no category $(1=$ no or $2=$ yes $)$, the children presented episodes of fever during the 14 days preceding enrollment of the day of interview.

Dietary diversity score: the categories were determined by first asking if the mothers had fed their children a particular type of food (30 different types) in the previous $24 \mathrm{~h}$. A score was then calculated to determine how many different type of food groups were consumed by children.

* Means the relation is significant at $P=0.05$ level.

Table 7 Linear regression final model analysis children aged 6-60 months in East Gojjam, April 2012.

\begin{tabular}{|c|c|c|c|c|c|c|}
\hline \multirow[t]{2}{*}{ Variables } & \multicolumn{3}{|c|}{ Unadjusted } & \multicolumn{3}{|c|}{ Adjusted } \\
\hline & Unstandardized coefficient & $t$ & $P$ & Unstandardized coefficient & $t$ & $P$ \\
\hline Categorized age $^{1}$ & -3.705 & -3.807 & $0.000^{*}$ & -3.674 & -3.801 & 0.000 \\
\hline $\begin{array}{l}\text { Total number of household } \\
\text { living on family land }{ }^{2}\end{array}$ & -0.779 & -0.672 & $0.006^{*}$ & -0.827 & -3.069 & 0.002 \\
\hline Dietary diversity score ${ }^{3}$ & -1.848 & -2.328 & $0.021 *$ & -1.262 & -1.632 & 0.104 \\
\hline
\end{tabular}

${ }^{\mathrm{T}}$ Infants and preschool children were categorized into three age groups: group 1 =6-10 months, group $2=18-22$ months and group 3 $=54-60$ months.

${ }^{2}$ Total number of household living on family land was analyzed per unit, but not categorized in the final model.

${ }^{3}$ The categories were determined by first asking if the mothers had fed their children a particular type of food (30 different types) in the previous $24 \mathrm{~h}$, and then a score was calculated to determine how many different types of food groups were consumed by children.

* Means the relation is significant at $P=0.05$ level.

the plasma zinc values in healthy preschool Australian children and found no significant age-dependent variation. Also, no association was found between serum zinc status and age among preschool child in 
Delhi [19] and Mexican [14]. However, the results of the study showed a significant difference in mean serum zinc concentration among 6-10 months age group compared to children in the higher age groups $(F=7.875, P=0.000)$. The result is consistent with the finding in Nepalese [20] and Brazilian preschool children [21], in which older children were found to have lower mean zinc levels than younger children. The analysis showed that older children had 3.67 $\mu \mathrm{g} / \mathrm{dL}$ (95\% CI: $-5.58,-1.77)$ lower serum zinc than children who were aged 6-10 months. This might be due to appropriate breastfeeding practices among younger age group, which might lead to better zinc status. Moreover, in this survey, the children's foods was based on cereals and legumes, so older children had lower plasma zinc concentrations than the younger children due to the low intake of zinc rich food, like animal product, as well as low bioavailability of zinc in cereals, legumes and vegetable origin food, since older children food is similar to that of adults.

The mean serum zinc status among male and female children was not statistically different. This findings is consistent with the previous other study in preschool children living in Delhi [19], Ecuadorian [22], Chinese [13] and Uganda [23]. But, Thurlow et al. [24] conducted a study on risk of zinc, iodine and other micronutrient deficiencies among school children in Thailand; the result revealed that male sex represented a risk factor for zinc deficiency.

In this study, the family size affected serum zinc status of children $(F=3.501, P=0.032)$. The result may be attributed to the extended family in the Ethiopian society. Zere and Mclntyre [25] reported the same results that family size is one of the factors, which affects child's nutritional status, and Reyes et al. [26] reported that the greatest protective effect of stunting was found in Mexican children cared exclusively by their mothers. The authors' result was inconsistent with the findings of Chinese study, in which children from small families ( $\leq 3$ persons) had a higher prevalence of low serum zinc than those from large families $(41 \%$ vs. $34 \%, P<0.001)$ [13]. In this study, when family members increased by one, serum zinc status of infant and children is more likely to decrease by $0.83 \mu \mathrm{g} / \mathrm{dL}$ ( $95 \% \mathrm{CI}:-1.36,-0.30)$. In the extended family, this might be because the mother cannot find enough time to care for the child, or might not be able to find healthy balanced food which indicated low quality of life in extended family.

Even if zinc deficiency is a widespread nutritional problem affecting low socio-economic status in both developed and developing countries [27, 28], some studies show that the socio-economic variables were only weakly associated with plasma zinc concentration in 6-35 months old Nepalese [20] and Chinese children [13]. The zinc status by wealth indexes did not significantly differ $(P>0.05)$, which might be because all of the participants were from the rural area and there was not enough variation among groups. The wealth index is relative (not absolute) measure of wealth. So, in relatively homogeneous population in the study area, it may lack power.

In this study, the mean serum zinc status and food security were not significantly associated. This might be the subsidiary demanding of the society.

Among the three age groups, 6-10 months (31.11\%) group was the lowest prevalence in stunting relative to 18-22 months (61.76\%) and 54-60 months (41.25\%) $(P=0.000)$ age group. This result is consistent with other studies in Ethiopia [29-31] and other developing country [32]. The result was consistent with a national nutrition survey, which was conducted in 2010 and revealed that in the Amhara region, $45 \%$ of children aged 6-59 months were stunted [33]. Anthropometric indices were not significantly associated with plasma zinc in Nepalese [20], Ghana [34], Uganda [23] and Vietnam in the study [35]. Stunted children are more likely to have lower zinc intake and plasma zinc concentration than non-stunted children $[16,29]$; however, stunting is a long-term cumulative effect of malnutrition, but the serum zinc status is a 
measurement of relatively recent nutritional status of children.

The concentration of plasma proteins maybe reduce because of increased protein catabolism, reduced synthesis during infection and intestinal protein loss during diarrhea. According to WHO and UNICEF report, zinc deficiency plays serious role in the cause of diarrhea, and it agrees with their recommendations to use of zinc supplementation for the treatment of childhood diarrhea [36]. A study in Uganda [23], Brazil [37] and Nepal [20] reported a decline in zinc concentrations in the serum of children with persistent diarrhea was significantly lower than that of children without diarrhea. However, presence of diarrhea and/or fever (used here as markers of inflammation) during the $14 \mathrm{~d}$ preceding the child's entrance to the study, was not associated with significant changes of zinc serum levels. This result is consistent with the result of Ferraz et al. [21], in which there was no strong correlation between serum zinc status of child and occurrence of diarrhea or fever at the enrollment time of child. This was probably due to the fact that at the time of data collection, the survey regarding presence of fever and/or previous episodes of diarrhea was conducted using an open interview depending on more accurate recall by parents, which is not always possible and may cause some bias in data collection.

Millions of people throughout the world may have inadequate levels of zinc in the diet, due to limited access to zinc-rich foods (animal products, oysters and shellfish) and due to the abundance of zinc inhibitors, such as phytates, common in plant-based diets [38]. Also, Kapil et al. [39] assessed the status of serum zinc status among tribal population in India. It was reported that $52.9 \%$ of tribal population had deficiency of zinc as revealed by their mean serum level, because their main staple diet was rice and maize. In East Gojjam community, the main staple diet was based on maize, sorghum, wheat, millet, bean and teff. At the time of data collection, most children consumed legume and cereal products in the previous
$24 \mathrm{~h}$. These cereals and legumes have high amount of phytic acid and the bioavailability of these foods is very low [40]. Statistical significant relationship was shown among children under five months who ate cereal and legume product and those who did not eat them $(P=0.01$ and $P=0.027)$, respectively. But these significances were diminished in linear regression model in dietary diversity score.

On the other hand, there was no mean serum zinc difference between children who ate meat and egg and children who did not eat them. This might be that the amount and frequency of meat consumption was not enough. Because organ, flesh meat and poultry products do not contain any known specific anti-nutritional factors that hinder zinc absorption. Eggs and dairy products are also rich in zinc and free of phytates, but they have slightly lower zinc than in organ and flesh foods [41]. Also, there was no mean serum zinc difference between infants and preschool children who ate vegetables and who did not eat. The higher order phytates, like inositol, hexaphosphate and pentaphosphates, found in most cereal, legumes and vegetables, are known to bind to zinc and form poorly soluble complexes that lead to reduced absorption from the intestinal lumen [42].

Based on the dietary diversity score, a child who consumed breast milk had a better zinc status than the children who ate food of group 1 and group $2(P=$ 0.020). This might be that children's complementary food is prepared predominantly from cereal and legume products, and such foods with high phytate may interfere with the absorption of zinc from breast milk [43]. Moreover, breast milk is the only dietary source of zinc for exclusively breastfed young infants and it remains a potentially important source of zinc for older infants and young children [44]. This is why infant had better zinc status than young children who ate food of group 1 and group 2 in this finding. In this study, the dietary score was significant when it was analyzed with unadjusted linear regression model, but it diminished when it was analyzed in adjusted linear 
regression model. This might be due to confounding factors, like age.

\section{Conclusions}

The prevalence of zinc deficiency of infant and preschool children was $57.1 \%$. According to IZiNCG, the zinc deficiency prevalence rate of greater than $20 \%$ is considered a public health concern in the infants and preschool children of East Gojjam. The main determinants of low serum zinc status of infant and preschool children were age and number of family members who lived on the same land. Dietary diversity partially influenced zinc status of infants and preschool children. Child health, food security, economic status, maternal education and stunting were not found to be associated with zinc status of infants and preschool children. Such potential deficiencies require urgent attention, including complementary food preparation education, nutrition education to reduce the phytate from the society staple food like cereals and legumes and strengthening family planning implementation.

\section{Recommendations}

Zinc deficiency is prevalent in a community due to low intake of zinc reach food. Direct approaches to increase the zinc status of infant and preschool children should aim at increasing the amount of zinc intake, either through dietary diversification and diet fortification, or through reducing the intake of zinc inhibitors by processing techniques. Dietary diversification to include more micronutrient rich foods in the diet is generally considered to be a sustainable approach in solving most micronutrient deficiencies. However, in the context of East Gojjam, advocating the increased inclusion of foods rich in bioavailable zinc in the diet will be difficult to achieve, since zinc rich foods are usually from animal and the relatively high cost of animal source foods make it less accessible to most poor families. In the study area, the children eat cereals and legumes products which have high content of phytate; so phytate reduction techniques, such as soaking, germination or fermentation at household level, should be encouraged in study areas. In addition to this, nutrition education is very important to mothers or caregivers about preparation of nutrient dense complementary foods for infant. Lastly, family planning implementation also is recommended in this area. A limitation of the present study is no information on acute infection indicator test, like C-reactive protein (CRP) and $\alpha-1$ acid glycoprotein (AGP), which likely reduced serum zinc concentration due to the redistribution of zinc from serum to the liver.

\section{Acknowledgments}

The authors would like to extend their heartfelt thanks to Dr. Samson Gebremedhin, who has guided in the statistical analysis. Special thanks go to all mothers and their children who volunteered for the study. The authors also acknowledge Addis Ababa University and Micronutrient Initiative for funding the study, and EHNRI and FMHACA for conducting laboratory analysis.

\section{References}

[1] Umeta, M., West, C. E., Verhoef, H., Haidar, J., and Hautvast, J. G. 2003. "Factors Associated with Stunting in Infants Aged 5-11 Months in the Dodota-Sire District, Rural Ethiopia." The Nutrition Journal 133 (4): 1064-9.

[2] Oyama, T., Matsuno, K., Kawamoto, T., Mitsudomi, T., Shirakusa, T., and Kodama, Y. 1994. "Efficiency of Serum Cooper/Zinc Ratio for Differential Diagnosis of Patients with and without Lung Cancer." Biol. Trace Element. Res. 42 (2): 115-27.

[3] World Food Programme (WFP) and Centers for Disease Control and Prevention (CDC). 2005. A Manual: Measuring and Interpreting Malnutrition and Mortality. Rome: WFP, 9-130.

[4] Black, R. E., Allen, L. H., Bhutta, Z. A., Caulfield, L. E., Onis, M., Ezzati, M., Mathers, C., and Rivera, J. 2008. "Maternal and Child Undernutrition: Global and Regional Exposures and Health Consequences." Lancet 371: 243-60.

[5] International Zinc Nutrition Consultative Group (IZiNCG). 2004. "Assessment of the Risk of Zinc Deficiency in Populations and Options for Its Control." Food Nutr. Bull. 25: 91-204. 

in East Gojjam, Amhara Region of Ethiopia

[6] Majlesi, F., Nikpoor, B., Golestan, B., and Sadre, F. 2001. "Growth Chart Study in Children under Five Years Old in Rural Area of Khoramabad Province.” Iranian Journal of Public Health 30: 107-10.

[7] Central Statistical Agency. 2011. "Ethiopia Demographic and Health Survey (EDHS)." Addis Ababa, Ethiopia. Accessed October 2012. http://www.unicef.org/ethiopia/ET_2011_EDHS.pdf.

[8] Swindale, A., and Bilinsk, P. 2006. Household Dietary Diversity Score (HDDS) for Measurement of Household Food Access: Indicator Guide, 2nd ed.. Washington, D.C.: FHI 360/FANTA.

[9] Coates, J., Swindale, A., and Bilinsk, P. 2007. Household Food Insecurity Access Scale (HFIAS) for Measurement of Household Food Access: Indicator Guide, 3rd ed.. Washington, D.C.: FHI 360/FANTA.

[10] World Health Organization (WHO). 2006. "Child Growth Stander: Training Course on Child Growth Assessment." Version 1. Accessed September 2011. www.who.int/childgrowth/publications/global_implemen tation.pdf.

[11] International Zinc Nutrition Consultative Group (IZiNCG). 2007. “Assessing Population Zinc Status with Serum Zinc Concentration.” Technical Brief No. 2. Accessed September 2011. www.zinc.org/health/resourceserve/izincg_technical_brie f_no_2.

[12] Getahun, Z., Urga, K., Ganebo, T., and Nigatu, A. 2001. "Review of the Status of Malnutrition and Trends in Ethiopia." Ethiop. J. Health Dev. 15 (2): 55-74.

[13] Liu, J., Ai, Y. X., Hanlon, A., Shi, Z., Dickerman, B., and Compher, C. 2011. "Micronutrients Deficiency and Associated Sociodemographic Factors in Chinese Children." World J. Pediatr. 7 (3): 217-23.

[14] Villalpando, S., Garcia-Guerra, A., Ramirez-Silva, C. I., Mejía-Rodríguez, F., Matute, G., Shamah-Levy, T., and Rivera, J. A. 2003. "Iron, Zinc and Iodide Status in Mexican Children under 12 Years and Women 12-49 Years of Age: A Probabilistic National Survey." Salud Publica Mex. 45 (4): 520-9.

[15] Barquera, S., Rivera, J. A., Safdie, M., Flores, M., Campos-Nonato, I., and Campirano, F. 2003. "Energy and Nutrient Intake in Preschool and School Age Mexican Children: National Nutrition Survey 1999." Salud Pública Méx. 45 (4): 540-50.

[16] Brown, K. H., Peerson, J. M., Rivera, J., and Allen, L. H. 2002. "Effect of Supplemental Zinc on the Growth and Serum Zinc Concentrations of Prepubertal Children: A Meta-Analysis of Randomized Controlled Trials.” Am. J. Clin. Nutr. 75 (6): 1062-71.

[17] Wouwe, V. J. P., and Waser, I. 1994. "Comparison between Total and Ultrafiltrable Serum Zinc as Test to
Diagnose Zinc Deficiency in Infants and Children.” Biol. Trace Elem. Res. 40 (3): 203-11.

[18] Karr, M., Mira, M., Causer, J., Earl, J., Alperstein, G., Wood, F., Fett, M. J., and Coakley, J. 1997. "Plasma and Serum Micronutrient Concentrations in Preschool Children." Acta Paediatrica 86 (7): 677-82.

[19] Dhingra, U., Hiremath, G., Menon, V. P., Dhingra, P., Sarkar, A., and Sazawal, S. 2009. "Zinc Deficiency: Descriptive Epidemiology and Morbidity among Preschool Children in Peri-Urban Population in Delhi, India.” J. Health Popul. Nutr. 27 (5): 632-9.

[20] Strand, T. A., Adhikari, R. K., Chandyo, R. K., Sharma, P. R., and Sommerfelt, H. 2004. "Predictors of Plasma Zinc Concentrations in Children with Acute Diarrhea." Am. J. Clin. Nutr. 79 (3): 451-6.

[21] Ferraz, I. S., Daneluzzi, J. C., Vannucchi, H., Jordão, J. A. A., Ricco, R. G., Del-Ciampo, L. A., Martinelli, C. E. J., Engelberg, A. A., Bonilha, L. R., and Custódio, V. I. 2007. "Zinc Serum Levels and Their Association with Vitamin A Deficiency in Preschool Children.” J. Pediatr (Rio) 83 (6): 512-7.

[22] Wuehler, S. E., Sempértegui, F., and Brown, K. H. 2008. "Dose-Response Trial of Prophylactic Zinc Supplements with or without Copper in Young Ecuadorian Children at Risk of Zinc Deficiency.” Am. J. Clin. Nutr. 87 (3): 723-33.

[23] Bitarakwate, E., Mworozi, E., and Kekitiinwa, A. 2003. "Serum Zinc Status of Children with Persistent Diarrhoea Admitted to the Diarrhoea Management Unit of Mulago Hospital, Uganda." Afr. Health Sci. 3 (2): 54-60.

[24] Thurlow, R. A., Winichagoon, P., Pongcharoen, T., Gowachirapant, S., Boonpraderm, A., Manger, M. S., Bailey, K. B., Wasantwisut, E., and Gibson, R. S. 2006. "Risk of Zinc, Iodine and Other Micronutrient Deficiencies among School Children in North East Thailand." Eur. J. Clin. Nutr. 60 (5): 623-32.

[25] Zere, E., and McIntyre, D. 2003. "Inequities in under Five Child Malnutrition in South Africa." International Journal of Equity Health 2 (7): 75-6.

[26] Reyes, H., Pérez-Cuevas, R., Sandoval, A., Castillo, R., Santos, J. I., Doubova, S. V., and Gutiérrez, G. 2004. "The Family as a Determinant of Stunting in Children Living in Conditions of Extreme Poverty: A Case-Control Study." BMC Public Health 4: 57.

[27] Abdalla, M., Saad, A., Abdullahi, H., Tinay, E., and Khattab, A. 2009. "Socio-Economic Aspects Influencing Food Consumption Patterns among Children under Age of Five in Rural Area of Sudan." Pakistan Journal of Nutrition 8 (5): 653-9.

[28] Ruz, M., Castillo-Duran, C., Lara, X., Odocro, J., Rebolledo, A., and Atalah, E. 1997. "A 14-Month Zinc Supplementation Trial in Apparently Healthy Chilean Preschool Children.” Am. J. Clin. Nutr. 66 (6): 1406-13. 

in East Gojjam, Amhara Region of Ethiopia

[29] Umeta, M., West, C. E., Haidar, J., Deurenberg, P., Hautvast, J. G. 2000. "Zinc Supplementation and Stunted Infants in Ethiopia: A Randomized Controlled Trial." Lancet 355: 2021-6.

[30] Yimer, G. 2006. "Malnutrition among Children in Southern Ethiopia: Levels and Risk Factors." Ethiop. J. Health Dev. 14 (3): 283-92.

[31] Teshome, B., Kogi-Makau, W., Getahun, Z., and Taye, G. 2009. "Magnitude and Determinants of Stunting in Children under Five Years of Age in Food Surplus Region of Ethiopia: The Case of West Gojam Zone." Ethiop. J. Health Dev. 23 (2): 98-106.

[32] Kumar, D., Goel, N. K., Mittal, P. C., and Misra, P. 2006. "Influence of Infant-Feeding Practices on Nutritional Status of Zinc and Whole Body Retention of Zn, Copper, Iron and Manganese in Rats." British Journal of Nutrition 34: 243-58.

[33] Ethiopian Health and Nutrition Research Institute. 2010. National Nutrition Baseline Survey Report for National Nutrition Program for Ethiopia.

[34] Takyi, E. E. K. 2004. "Hair Zinc Status and Its Correlation with Height Indicator in Preschool and School Children from a Mixed Income, Low Density (Mild) Community in Southern Ghana." East African Medical Journal 81 (1): 42-6.

[35] Nhien, N., Khan, N. C., Ninh, N. X., Huan, P., Hop, L. T., Lam, N. T., Ota, F., Yabutani, T., Hoa, V. Q., Motonaka, J., Nishikawa, T., and Nakaya, Y. 2008. "Micronutrient Deficiencies and Anemia among Preschool Children in Rural Vietnam.” Asia Pac. J. Clin. Nutr. 17 (1): 48-55.

[36] World Health Organization (WHO) and United Nations Children's Fund (UNICEF). 2004. "Clinical Management of Acute Diarrhea." WHO-UNICEF Joint Statement, Geneva. $\quad$ Accessed July 2011.
http://www.unicef.org/publications/files/ENAcute_Diarrh oea_reprint.pdf.

[37] Borges, C. V. D., Veiga, A. P. B., Barroso, G. S., Jesus, E. F. O., Serpa, R. F. B., Moreira, S., and Salles-Costa, R. 2007. "Association among Serum Concentration of Minerals, Anthropometric Indices and Diarrhea in Low Income Children in the Metropolitan Region of Rio de Janeiro, Brazil." Rev. Nutr. 20 (2): 159-69.

[38] Sandstead, H. H. 1991. "Zinc Deficiency: A Public Health Problem?” Am. J. Dis. Child. 145 (8): 853-9.

[39] Kapil, U., Singh, P., and Pathak, P. 2003. "Serum Zinc Levels amongst Tribal Population in a District of Jharkhand State, India: A Pilot Study.” Eastern Journal of Medicine 8 (2): 33-4.

[40] Umeta, M., West, C. E., and Fufa, H. 2005. "Content of Zinc, Iron, Calcium and Their Absorption Inhibitors in Foods Commonly Consumed in Ethiopia." Journal of Food Composition and Analysis 18 (8): 803-17.

[41] Brown, K. H., and Wuehler, S. E. 2000. Zinc and Human Health: Results of Recent Trials and Implications for Program Interventions and Research. Ottawa, Canada: Micronutrient Initiative.

[42] Krebs, N. F. 2000. "Dietary Zinc and Iron Sources, Physical Growth and Cognitive Development of Breastfed Infants." J. Nutr. 130 (2): 358-60.

[43] Krebs, N. F., and Hambidge, K. M. 2007. "Complementary Feeding: Clinically Relevant Factors Affecting Timing and Composition.” Am. J. Clin. Nutr. 85 (2): 639-45.

[44] Brown, K. H., Engle-Stone, R., Krebs, N. F., and Peerson, J. M. 2009. "Dietary Intervention Strategies to Enhance Zinc Nutrition: Promotion and Support of Breastfeeding for Infants and Young Children.” Food Nutr. Bull. 30 (1): 144-71. 